\title{
QUANTIFYING THE RESPONSE OF STEEL COLUMNS TO MULTI-AXIS LONG-DURATION BLAST AND THERMAL LOADING
}

\author{
LAURA MCFADZEAN \& SIMON K. CLUBLEY \\ Blast Engineering Research Group, Faculty of Engineering and the Environment, University of Southampton, UK
}

\begin{abstract}
Columns are an integral part of a steel framed structure, responsible for carrying load to the foundations. If the integrity of a column is compromised due to damage, such as from blast, incipient partial or total collapse of a structure can occur. The response of a column to blast can increase for a number of reasons e.g. the blast is long-duration in nature, where long-duration is defined as the positive duration in excess of $100 \mathrm{~ms}$, the blast arrives at an oblique angle of incidence or the column is also subject to a thermal load. While the effects of each have been considered separately, there is no research on the response to a combination. This paper reports on the effect of multi-axis long-duration thermal and blast loading on the response of a steel column. Numerical modelling was used to determine the blast load and the structural response of the column. The results show that column response to multi-axis and thermal loading individually increases due to a combination of projected area, weak axis and shielding effects and thermal softening respectively. Additionally, the response is increased further when multi-axis and thermal loading are considered together.
\end{abstract}

Keywords: long-duration blast loading, thermal loading, synergistic response, multi-axis response, steel column.

\section{INTRODUCTION}

In December 2005, a vapour cloud explosion occurred at an oil storage depot in Buncefield, UK. Large steel framed warehouses were damaged in the far-field, to an extent that most of the buildings required demolition or abandonment for extended periods of time while repairs were carried out [1]. A large explosion such as the Buncefield event is characteristic of longduration blast where the positive phase duration is in excess of $100 \mathrm{~ms}$. Long-duration explosions produce large impulses that can cause greater damage to steel frames than a conventional explosion with the same peak static overpressure. This computational study considers steel columns subject to long-duration blast loading and the work has been experimentally benchmarked using previous research in the air blast tunnel (ABT) at MoD Shoeburyness [2], [3]. The ABT is a 200m long, explosively driven shock-tube and is one of a small number of test facilities capable of producing a long-duration blast environment (Fig. 1). The facility has been used in a number of experiments investigating the effects of long-duration blast loading on structural elements [4]-[8].

Steel column response and hence damage state from long-duration blast loading can be enhanced due to a number of factors such as thermal load from an explosive thermal flux [3], [9], angle of incidence [2] and axial compression [10], [11]. A combination of any of these factors with blast loading can produce a greater response than expected from blast only. These phenomena form the basis of this computational study which investigates a $4 \mathrm{~m}$ tall, $203 \times 203 \times 71$ UKC I-section column subject to a combination of long-duration thermal and blast load at 5 orientation steps from $0-90^{\circ}$. The column is assumed to be an edge column within a one-storey building connected to three $6 \mathrm{~m}$ long $305 \times 165 \times 40$ UKB carrying a permanent action from the roof of $1.35 \mathrm{kNm}^{-2}$, any cladding is assumed to fail upon arrival of the blast load due to near instantaneous over-matching. 


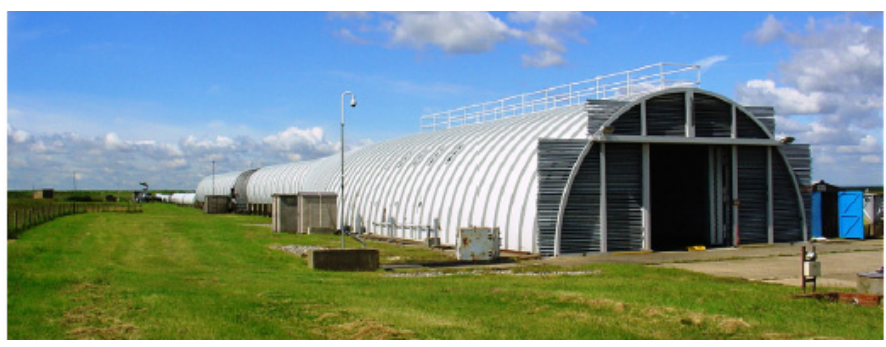

Figure 1: Air blast tunnel (ABT) at MoD Shoeburyness [8].

\section{COMPUTATIONAL SET-UP}

\subsection{Computational fluid dynamics}

ANSYS Autodyn [12] was used to model blast loading for the study. The hydrocode showed good agreement with experimental pressures on column surfaces from the ABT with positive phase duration, $t_{d}=150 \mathrm{~ms}$, peak overpressure, $p_{s}=55 \mathrm{kPa}$ and impulse, $i_{s}=3300 \mathrm{kPa} \cdot \mathrm{ms}$ [2]. Therefore, it was considered accurate for generating surface pressures from a larger blast event; $t_{d}=156 \mathrm{~ms}, p_{s}=175 \mathrm{kPa}$ and $i_{s}=8450 \mathrm{kPa}$. A $1 \mathrm{D}$ wedge was used to model the incident blast wave before any reflection occurred in the vicinity of the column. A spherical charge of TNT with density of $1.65 \mathrm{gcm}^{-3}$ and radius of $5.25 \mathrm{~m}$ was detonated within air at atmospheric pressure and temperature, the problem was resolved using an Euler-Godunov multi-material solver until the blast wavefront arrived at the end of the wedge $200 \mathrm{~m}$ from detonation. The $1 \mathrm{D}$ results file was remapped into the 2D domain containing only atmospheric air, the location of remap changed with orientation but was consistently $200 \mathrm{~m}$ from the nearest column surface. The domain was $180 \mathrm{~m}$ by $180 \mathrm{~m}$ in size to ensure any reflection from boundaries, despite being defined as transmissive, did not interact with the column or incident gauge. A total of 1 million cells were specified across the entire domain and a re-zoning feature was used where a $5 \mathrm{~mm}$ cell size could be specified at the centre of the domain and increased out to the edges in order to draw intricate geometry without significantly increasing the run time. A number of unused cells were used to model column geometry which simulated the column as a rigid body with reflecting surfaces. Gauges were used to monitor the blast pressures on each surface of the column, three gauges were distributed evenly across each surface to produce an average. A Euler-FCT (Flux Corrected Transport) solver was used over an Euler-Godunov solver to increase accuracy using an antidiffusion step which corrects for numerical diffusion otherwise introduced into the solution [13].

\subsection{Thermal loading}

During detonation of an explosion, extremely high temperatures are reached within the fireball. For long-duration explosions these temperatures lead to a high proportion of thermal energy being emitted in the form of a thermal pulse. The power and duration of this thermal pulse are dependent upon the explosive charge size and the proportion of power that arrives at a structure depends on atmospheric conditions and stand-off distance. The thermal pulse travels at the speed of light and therefore reaches a structure prior to the blast wave which travels at supersonic speed. The thermal flux pulse for the chosen explosion was determined 
from a number of empirical equations [14] and is shown in Fig. 2, this was transformed to an equivalent steel surface temperature using eqn (1) and an absorption coefficient of 0.79 for oxidised steel [15]

$$
J=\sigma T^{4}
$$

where: $J=$ thermal power $\left(\mathrm{J} \cdot \mathrm{s}^{-1} \cdot \mathrm{m}^{-2}\right), T=$ temperature $\left({ }^{\circ} \mathrm{K}\right)$ and $\sigma=$ Stefan-Boltzmann constant $\left(5.6704 \times 10^{-8} \mathrm{~J} \cdot \mathrm{s}^{-1} \cdot \mathrm{m}^{-2} \cdot{ }^{\circ} \mathrm{K}^{-4}\right)$.

\subsection{Finite element analysis}

ANSYS Mechanical was used to solve the transient, non-linear thermal and structural analyses. A modified Johnson-Cook material model [9] was used to define the response of S355 structural steel to high strain rate and high temperature loading; temperature dependent thermal conductivity and specific heat for carbon steel were also defined. The column geometry was meshed with $10 \mathrm{~mm}$ quadratic solid elements (SOLID95), this element size and type was determined to be the most accurate and efficient for both thermal and structural analyses in a preceding sensitivity study. A transient thermal analysis was conducted first where the previously defined surface temperatures were applied to exposed surfaces of the column, assuming the thermal pulse arrives from the same direction as the blast load. Body temperature results were then imported into the transient structural analysis. A pinned support condition was applied to the base of the column and a spring support at the top to represent resistance from connecting beams [16]. All orientated columns were configured at an angle to the global axis and the blast pressure profile for each surface from Autodyn was applied in the global $\mathrm{X}$ and $\mathrm{Z}$ directions. A Rayleigh damping ratio of 5\% was used and an axial load was applied to the column to represent dead load from the connecting beams and roof.

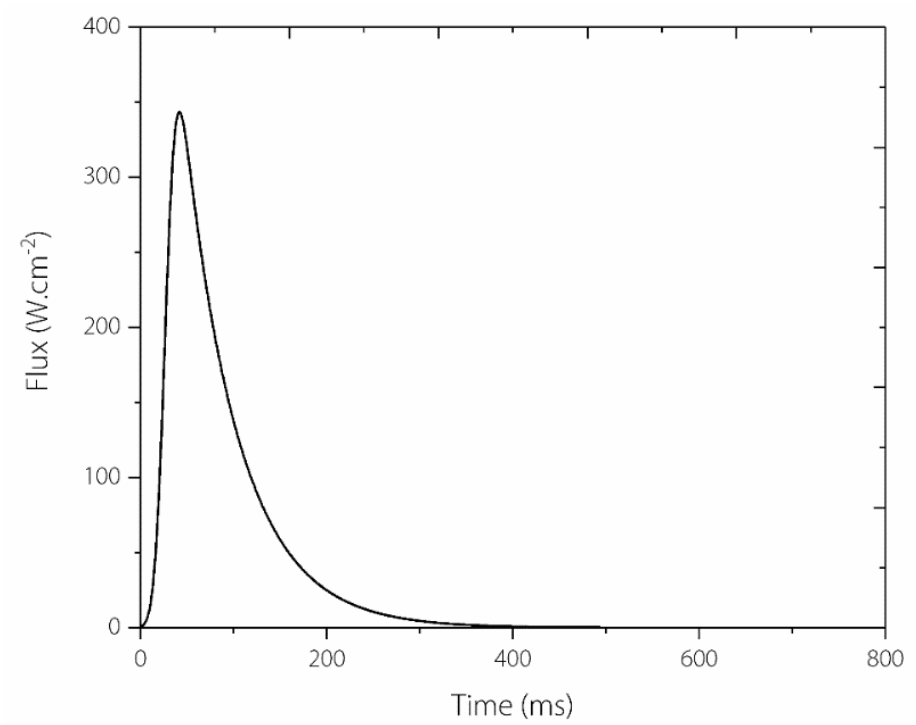

Figure 2: Thermal flux profile for blast parameters: $\mathrm{t}_{d}=156 \mathrm{~ms}, \mathrm{p}_{\mathrm{s}}=175 \mathrm{kPa}, \mathrm{i}_{\mathrm{s}}=8450 \mathrm{kPa} . \mathrm{ms}$. 


\section{COMPUTATIONAL RESULTS AND ANALYSIS}

\subsection{Computational fluid dynamics}

Fig. 3 shows the incident pressure and impulse profiles obtained from the 2D-Autodyn analysis, showing that blast wave parameters were consistent across the five models and suitably matched the required parameters. Fig. 4 shows the change in surface impulse with orientation, the total impulse of surfaces 1,2 and 3 increased with orientation from $0^{\circ}$ to $60^{\circ}$ as they became more exposed to the blast wave front while there was little difference from $60^{\circ}$ to $90^{\circ}$. Surfaces $4,5,6$ and 7 experienced small surface impulse because they were shielded from the blast and were relatively consistent throughout each orientation, except for a decrease for surface 4 at 450 which was the result of either the wave taking longer to equalise around this orientation or the inviscid hydrocode's limitation on modelling aerodynamic effects (such as wake and vorticity) around bluff objects. Surface 8 experienced a decrease in surface impulse with orientation from $0^{\circ}$ to $90^{\circ}$ due to increased shielding. At a 450 orientation, surfaces $1,2,3$ and 8 experienced a similar total impulse due to being equally exposed to the blast. Fig. 5 shows how variations in impulse and projected area of each surface govern the net impulse experienced by each orientation in the blast direction, $\mathrm{Z}$ and transverse direction, $X$. The $0^{\circ}$ and $90^{\circ}$ orientations experienced a similar net impulse in the blast direction and zero impulse in the transverse directions due to symmetry allowing diffraction pressures to equalise. The $45^{\circ}$ orientation experienced the highest net impulse in both the blast and transverse directions closely followed by $30^{\circ}$ and $60^{\circ}$, this was due to a combination of projected area and surface impulse.

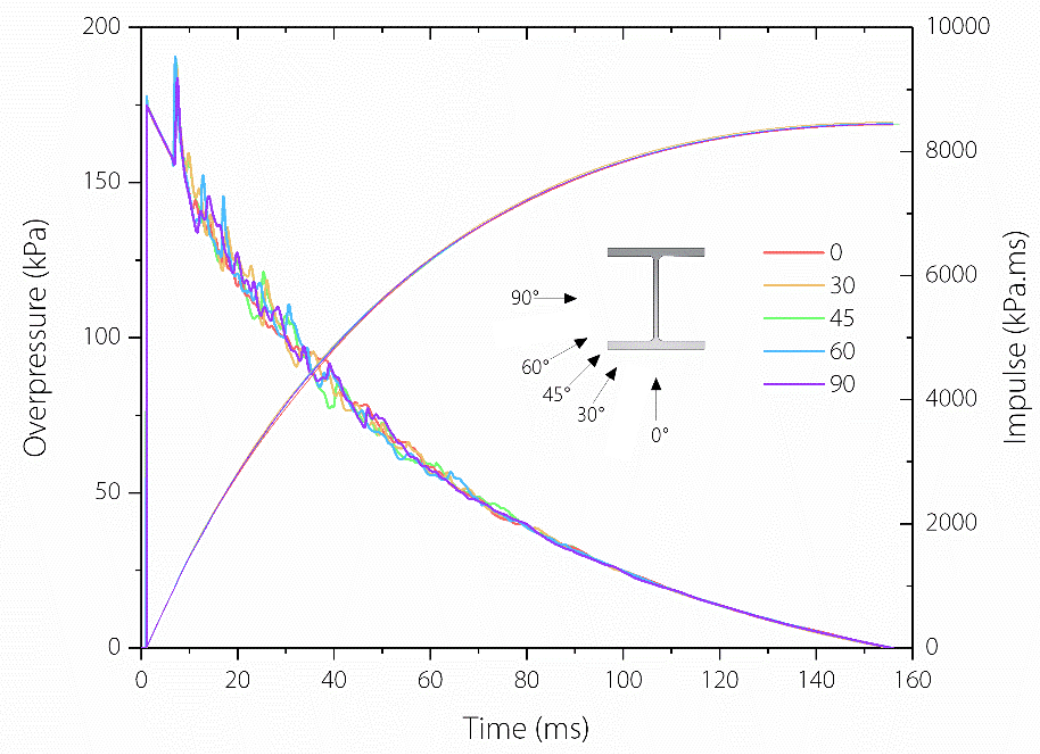

Figure 3: AUTODYN incident pressure and impulse histories. 


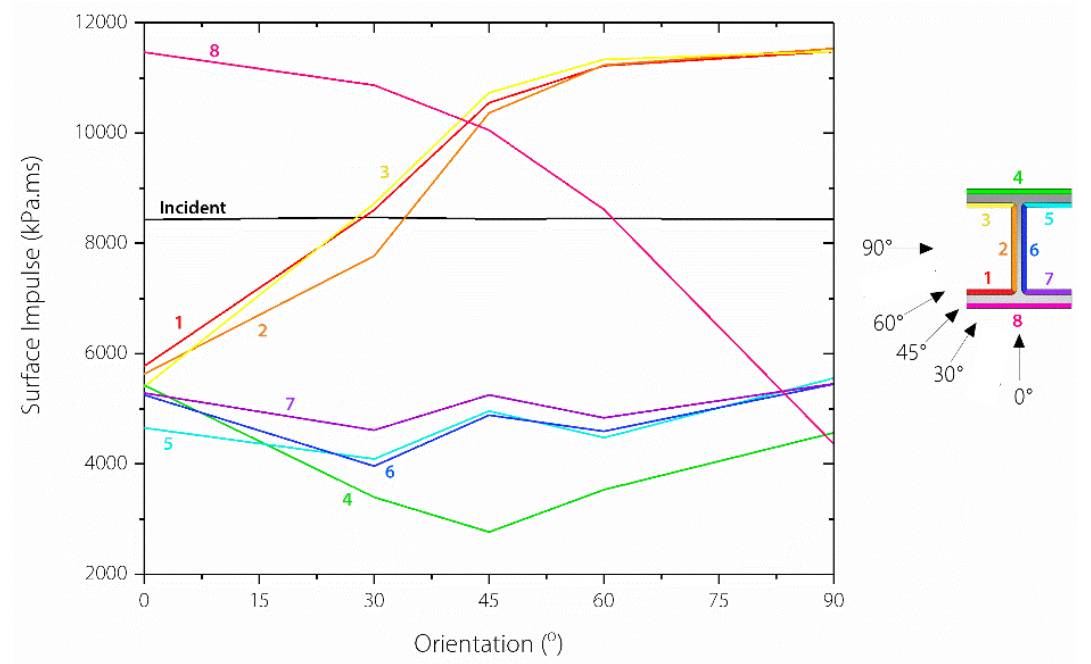

Figure 4: AUTODYN surface impulse and orientation.

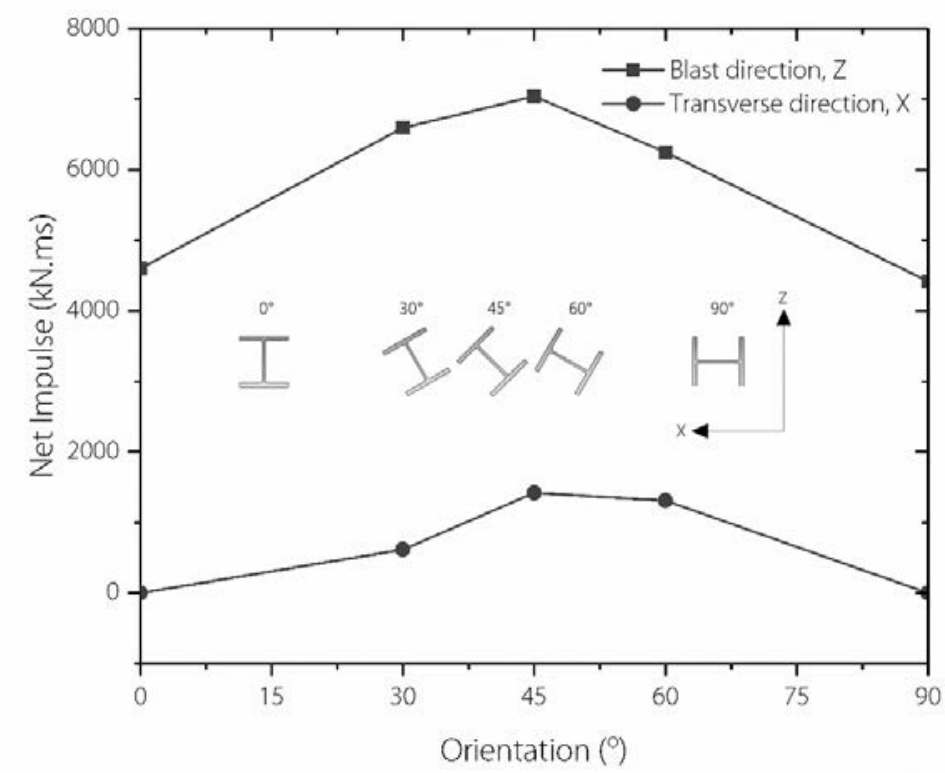

Figure 5: Section net impulse and orientation.

\subsection{Finite element analysis}

Each column exhibited maximum displacement at the top of the column; Fig. 6 shows the peak total displacement in all ten situations. 


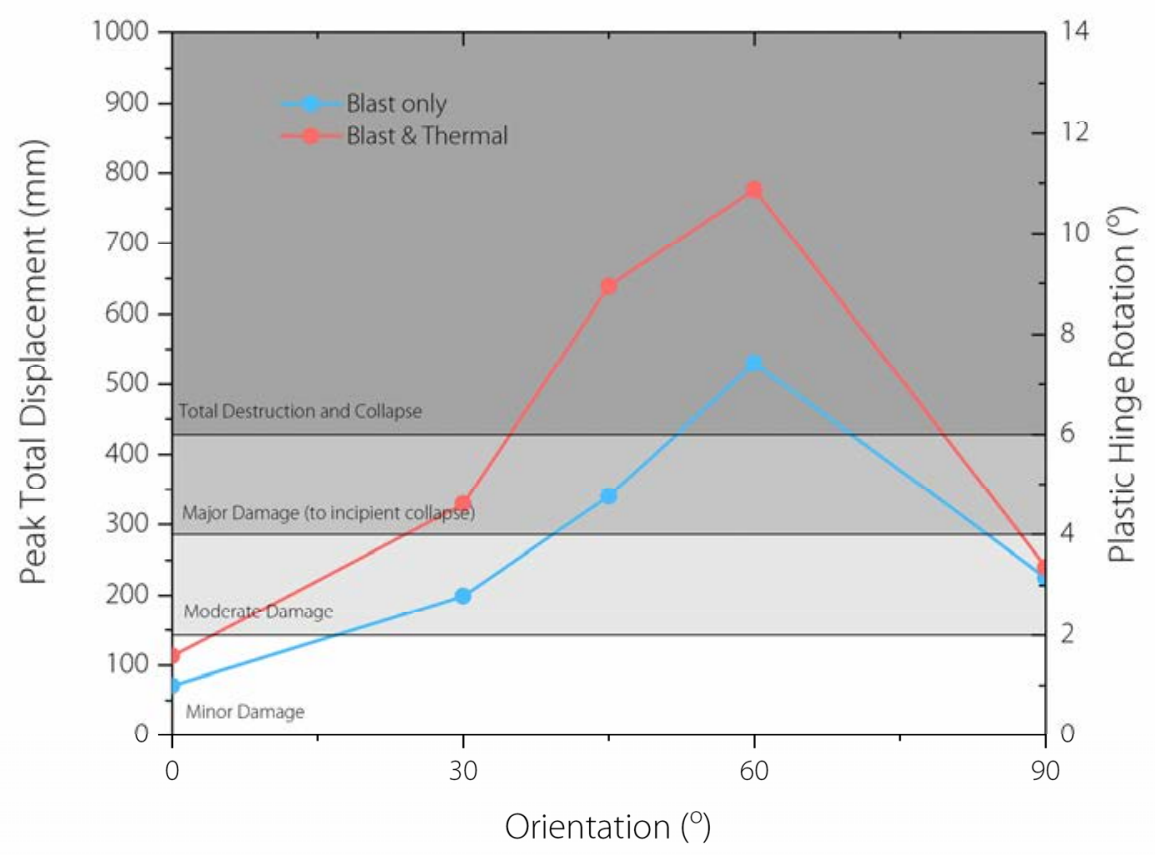

Figure 6: Peak total displacement of columns subject to blast only and blast and thermal loading at five orientations.

When subjected to a blast only load, the $60^{\circ}$ case was the most critical with the peak displacement approximately 7.5 times the peak displacement of the $0^{\circ}$ orientation (strong axis). Based on failure rotation guidelines for steel buildings [17]. Fig. 6 also shows the level of damage that each situation would result in if occurring within a frame. The $0^{\circ}$ blast only case resulted in minor damage, when the column was instead loaded at a $30^{\circ}$ or $90^{\circ}$ angle the damage level increased to moderate, a $45^{\circ}$ angle led to major damage and incipient collapse and a $60^{\circ}$ angle importantly resulted in total destruction and collapse.

When subjected to both blast and thermal loading, the peak displacements of each orientation increased. The $0^{\circ}$ orientation showed the smallest response of $113 \mathrm{~mm}$ which was an increase of 1.6 from blast only conditions, the $90^{\circ}$ orientation experienced the smallest increase in response of 1.1 times; both orientations remained in the same level of damage as from blast only. The $60^{\circ}$ orientation was again the most critical, with the peak displacement 1.5 and 11 times greater than the $60^{\circ}$ and $0^{\circ}$ blast only cases respectively. The $30^{\circ}$ and $45^{\circ}$ orientations showed an increase in response of 1.5 and 1.9 respectively compared to blast only, both resulting in a damage state within the next level.

\section{DISCUSSION}

Results from this study strongly indicate that multi-axis effects can significantly change the response of a column due to a combination of section strength and net impulse which is a function of projected area of the section. The $30^{\circ}, 45^{\circ}$ and $60^{\circ}$ orientations were subjected to a larger net impulse than $0^{\circ}$ and $90^{\circ}$ which is reflected in the structural response. Despite the $45^{\circ}$ case being subject to the highest net impulse in the blast direction it showed a smaller displacement than the $60^{\circ}$ orientation under blast only conditions, implying that the $60^{\circ}$ 
orientation was the weakest section and section strength has a greater effect on response than net impulse (providing the same blast conditions are considered).

For the investigated blast conditions, it is suggested that a thermal load increases the response of each orientation due to the decrease in material strength, this is because the thermal softening has a greater effect than the increase from high strain rate. An average increased peak response of 1.5 was seen for all orientations. For $30^{\circ}$ and $45^{\circ}$ inclusion of a thermal load caused the damage state to be within the next level. While minor damage would be expected for an orientation of $0^{\circ}$ subjected to the blast pressure and thermal load, major damage at a minimum would be expected in the oblique angles showing how important it is to consider both multi-axis and synergistic effects.

\section{CONCLUSIONS}

Both multi-axis and synergistic effects can cause significant changes in the response of a column. For the blast load considered, the response and damage state of a column can vary with orientation from minor damage to total destruction. Of the five orientations considered, $60^{\circ}$ was the most critical. When a thermal load is introduced, the peak damage state of each orientation is increased with certain orientations being increased into the next damage level. This study shows that while a building may be protected from collapse when loaded by blast only at a normal angle this is not necessarily true when loaded at an oblique angle with a preceding thermal pulse.

\section{ACKNOWLEDGEMENTS}

The authors would like to express gratitude to the UK Ministry of Defence for allowing the use of experimental data from the blast testing facilities at MoD Shoeburyness. All data obtained while using these facilities remains the property of the UK MoD. The permission to utilise these results within this paper is gratefully acknowledged. The authors wish to thank AWE plc for financial support.

\section{REFERENCES}

[1] Atkinson, G., Blast damage to storage tanks and steel-clad buildings. Process Safety and Environmental Protection, 89, pp. 382-390, 2011.

DOI: $10.1016 /$ j.psep.2011.06.020.

[2] Denny, J., Investigating Multi-Axis Long-Duration Blast Response of Steel Column Sections, Southampton, 2017.

[3] Clough, L., Synergistic response of steel structures to thermal and blast loading, Southampton, 2016.

[4] Denny, J. \& Clubley, S.K., Multi-axis long-duration blast interaction with I-shape steel sections. Proceedings of the Twenty Fourth Military Aspects of Blast and Shock Conference, Halifax, 2016.

[5] Monk, S. \& Clubley, S.K., Quantifying the influence of aspect ratio on window failure when subject to long-duration blast loading. Proceedings of the Seventeenth International Symposium on the Interaction of the Effects of Munitions with Structures, Bad Neuenahr, 2017.

[6] Johns, R. \& Clubley, S.K., The influence of structural arrangement on long-duration blast response of annealed glazing. International Journal of Solids and Structures, 9798, pp. 370-388, 2016. DOI: 10.1016/j.ijsolstr.2016.07.012.

[7] Johns, R. \& Clubley, S.K., Experimental analysis of small masonry panels subject to long duration blast loading. Proceedings of the Sixteenth International Symposium on the Interaction of the Effects of Munitions with Structures, Destin, 2015. 
[8] Clubley, S.K., Non-linear long duration blast loading of cylindrical shell structures. Engineering Structures, 59, pp. 113-126, 2014. DOI: 10.1016/j.engstruct.2013.10.030.

[9] Forni D., Chiai, B. \& Cadoni, E., High strain rate response of S355 at high temperatures. Materials and Design, 94, pp. 467-478, 2016. DOI: 10.1016/j.engstruct.2016.04.013.

[10] McConnell, J. \& Brown, H., Evaluation of pregressive collapse alternate load path analyses in designing for blast resistance of steel columns. Engineering Structures, 33, pp. 2899-2909, 2011. DOI: 10.1016/j.engstruct.2011.06.014.

[11] Nassr, A., Razaquur, A., Tait, B., Campidelli, M. \& Foo, S., Strength and stability of steel beam columns under blast load. International Journal of Impact Engineering, $\mathbf{5 5}$, pp. 34-48, 2013. DOI: 10.1016/j.ijimpeng.2012.11.010.

[12] ANSYS, Autodyn, Release 17.1, 2016.

[13] Børve, S., Bjerke, A., Omang, M. \& Svinsås, E., A comparison of AUTODYN and RSPH on two-dimensional shock wave problems, Norwegian Defence Research Establishment (FFI): Oslo, 2009.

[14] Glasstone, S. \& Dolan, P., The Effects of Nuclear Weapons, United States Department of Defense, 1977.

[15] Wang, Y., Burgess, I., Wald, F. \& Gillie, M., Performance Based Fire Engineering of Structures. First ed. s.l., CRC Press, 2012.

[16] Shepherd, P. \& Burgess, I., On the buckling of axially restrained steel columns in fire. Engineering Structures, 33, pp. 2832-2838, 2011.

DOI: $10.1016 /$ j.engstruct.2011.06.007.

[17] Center for Chemical Process Safety, Guidelines for Evaluating Process Plant Buildings for External Explosions and Fires, s.l., American Institute of Chemical Engineers, 1996. 